\title{
Molecular Markers to Select for the $j$-2-mediated Jointless Pedicel in Tomato
}

\author{
Tong Geon Lee ${ }^{1,2}$ \\ Gulf Coast Research and Education Center, University of Florida, \\ Wimauma, FL 33598; and Horticultural Sciences Department, University \\ of Florida, Gainesville, FL 32611
}

\author{
Reza Shekasteband ${ }^{1}$ \\ Gulf Coast Research and Education Center, University of Florida, \\ Wimauma, FL 33598
}

Naama Menda and Lukas A. Mueller
Boyce Thompson Institute, 533 Tower Road, Ithaca, NY 14853

Samuel F. Hutton

Gulf Coast Research and Education Center, University of Florida, Wimauma, FL 33598; and Horticultural Sciences Department, University of Florida, Gainesville, FL 32611

Additional index words. mechanical harvest, marker-assisted selection, fresh-market tomato

\begin{abstract}
The jointless pedicel trait of tomato conferred by the $j-2$ gene is widely used in processing markets for stem-free removal of fruit to accommodate mechanized harvest. Although current utilization of $\boldsymbol{j}$ - 2 for fresh-market tomato breeding is limited, interest in this trait may increase as breeders seek to address high labor costs through the development of mechanically harvestable cultivars for the fresh market. Yet, the introduction of this trait into new market classes heavily relies on phenotypic selection because there are presently no high-throughput methods available to genotype $j$ - 2 . Reliable, high-throughput molecular markers to genotype the presence/absence of $j-2$ for selective breeding were developed. The molecular markers described here use the highresolution DNA melting analysis (HRM) genotyping with single-nucleotide polymorphism (SNP) and derived cleaved amplified polymorphic sequence (dCAPS)-based genotyping. Two separate HRM-based markers target the $j-2$ on chromosome 12 or a linked sequence region $3.5 \mathrm{Mbp}$ apart from the gene, and a dCAPS marker resides on the latter. We demonstrate the association between each marker and the jointless pedicel phenotype using segregating populations of diverse filial generations in multiple genetic backgrounds. These markers provide a useful resource for marker-assisted selection of $j-2$ in breeding populations.
\end{abstract}

Tomato (Solanum lycopersicum L.) is the most valuable horticultural crop worldwide (Food and Agriculture Organization of the United Nations; http:/www.fao.org/faostat/ en/\#data/QC/metadata). Fresh-market and processing tomatoes, the two most commonly consumed types of tomatoes, are economically important in many countries, including the United States [United States Department of Agriculture Economic Research Service (USDA ERS); www.ers.usda.gov/topics/crops/ vegetables-pulses/tomatoes]. Nonetheless,

Received for publication 7 Nov. 2017. Accepted for publication 15 Dec. 2017.

This work was supported by awards 020726 and 024065 funded through the Florida Department of Agriculture and Consumer Services Specialty Crop Block Grant Program.

${ }^{1}$ These authors contributed equally to this work. ${ }^{2}$ Corresponding author. E-mail: tonggeonlee@ufl. edu.

This is an open access article distributed under the CC BY-NC-ND license (http://creativecommons. org/licenses/by-nc-nd/4.0/). further improvement in horticultural performance is necessary to achieve future productivity gains, especially given the rapidly growing labor costs and recent trends in uncertainty about trained labors (California Tomato Growers Association; www.ctga.org, Florida Tomato Committee; www.floridatomatoes. org, USDA ERS).

A major change among agricultural industries has been a shift toward farm machinery to achieve higher levels of productivity and market value (Pardey et al., 2016; Zahara and Johnson, 1981). Unlike processing tomatoes that have been successfully adapted for mechanized harvest, production of freshmarket tomatoes continues to rely on manual labor for harvesting and other common cultural practices (such as staking, tying, and pruning), which can account for as much as a half of the total production cost (Davis and Estes, 1993; USDA ERS). Thus, there is a significant need to research traits which will facilitate a transition to broader mechanization in fresh-market tomato production.

Tomato inflorescences typically have an abscission zone (joint) in the pedicel of each flower. Detachment of the fruit at this joint at harvest results in the calyx and stem remaining attached to the fruit, which can in turn puncture or otherwise damage neighboring fruit. The jointless pedicel trait was first reported by Butler (1936). Because jointless tomatoes lack an abscission zone in the pedicel, the calyx and stem remain attached to the plant, enabling of stem-free harvest of fruit. Hand harvesting of jointed pedicel tomatoes involves the manual removal of any attached stems from fruit, but jointless pedicels are an essential component for maintaining fruit quality and marketability in cultivars intended for mechanical harvest (Scott et al., 2013; Zahara and Scheuerman, 1988).

Two recessive genes known to mediate the jointless pedicels in tomato have been identified. The first gene, jointless $(j)$, is located on chromosome 11 and was identified from $S$. lycopersicum accession LA624 (Rick, 1980; Wing et al., 1994). Mao et al. (2000) determined that $j$ was a MADS-box gene controlling tomato flower abscission zone development. Later, an alternative allele, jointless-2 ( $j$-2; Rick, 1956) was identified in S. cheesmanii accession LA166 and also as a spontaneous mutation in cultivated tomato (Reynard, 1961). $j$-2 was mapped to an $\approx 6$-Mbp interval in the centromeric region on chromosome 12 (Budiman et al., 2004; Yang et al., 2005; Zhang et al., 2000). Recent progress in understanding the molecular characteristics of the jointless trait has revealed the underlying gene, a MADS-box transcription factor 11 gene (Solyc12g038510) of $S$. lycopersicum (the jointed pedicel traitderived allele) (Soyk et al., 2017), and determined that loss of function mutations in this gene resulted in the jointless inflorescence. Hence, mutated versions of Solyc 12g038510 are referred to as $j-2$ in the present study.

$j-2$ has been broadly used by tomato breeding programs in the United States and around the world. However, current selection methods rely predominantly on phenotypic expression at flowering or thereafter. Marker resources to aid in selection efforts are limited. In the late $1990 \mathrm{~s}$, Zhang et al. (2000) developed a random amplified polymorphic DNA (RAPD) marker for $j-2$ which has been used in independent research efforts (Budiman et al., 2004; Yang et al., 2005). However, the marker system is not fully feasible because of the cumbersome process of the RAPD system and difficulty in its reproduction. The CAPS marker tagging $j-2$ alleles (Soyk et al., 2017) is detected via a gel-based polymerase chain reaction (PCR) image and is not immediately useful for highthroughput genotyping. Thus, a practical means to select for this trait could be very helpful for introducing and selecting the jointless trait in tomato germplasm, especially for fresh-market backgrounds which are predominantly jointed.

The objective of this project was to develop molecular markers linked to the $j$-2 locus that can be useful for marker-assisted selection (MAS). We used whole-genome 


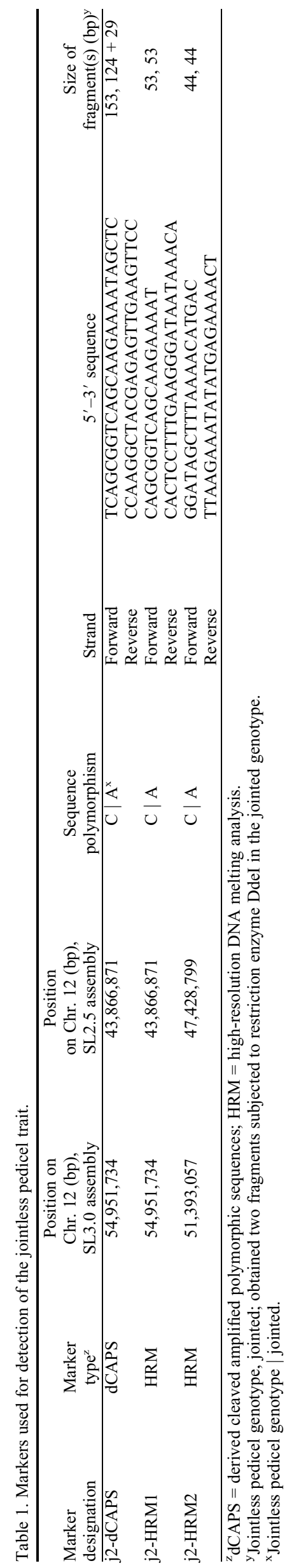

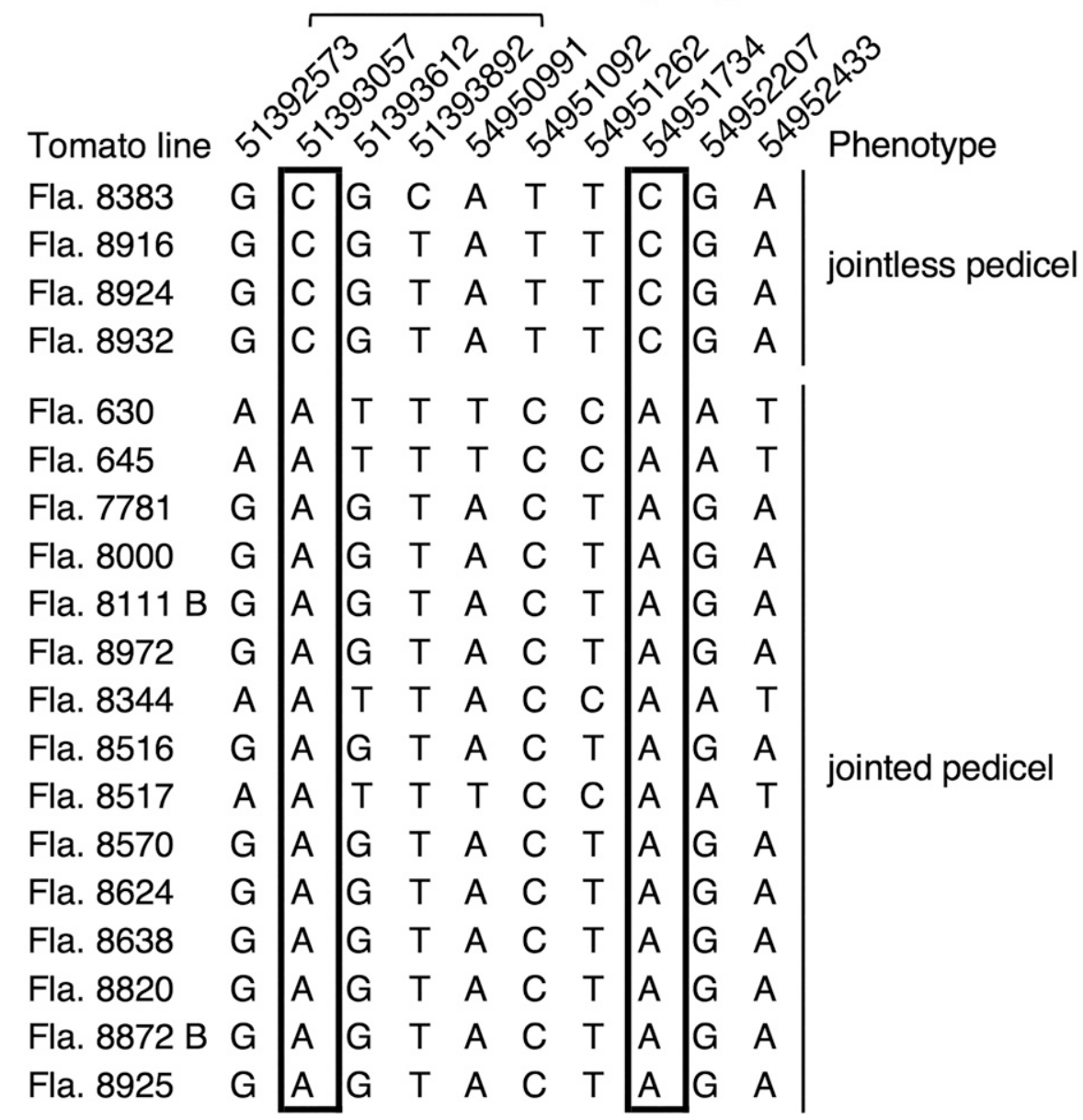

Fig. 1. Identification of single-nucleotide polymorphisms (SNPs) near the jointless pedicel locus $(j-2)$ in 19 tomato lines. Boxes indicate the SNPs used for the parker development in this study. SNPs in the 1$\mathrm{kb}$ region surrounding each box are shown. Nucleotide positions are from the SL3.0 version of Heinz 1706 reference. Positions in the $J-2$ gene (Solyc12g038510) are marked.

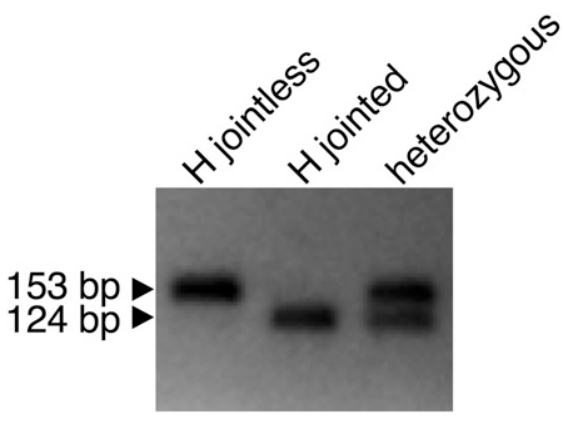

Fig. 2. Results of dCAPS analysis using an SNP located near the $j-2$. In homozygous jointed pedicel or heterozygous genotypes, a 20-bp fragment by restriction enzyme digestion is not captured in this figure. "H jointless" and " $\mathrm{H}$ jointed" represent homozygous jointless pedicel and homozygous jointed pedicel, respectively.

sequencing of jointless and jointed tomato lines to identify SNPs proximal to the locus.

\section{Materials and Methods}

Plant material. Nineteen inbred lines from the University of Florida Institute of
Food and Agricultural Sciences (UF/IFAS) tomato breeding program were selected for whole-genome sequencing to identify polymorphisms near the $j-2$ locus. These included four jointless inbreds, Fla. 8383, Fla. 8916, Fla. 8924, and Fla. 8932; and 15 jointed inbreds, Fla. 630, Fla. 645, Fla. 7781, Fla. 8000, Fla. 8111B, Fla. 8297, Fla. 8344, Fla. 8516, Fla. 8517, Fla. 8570, Fla. 8624, Fla. 8638, Fla. 8820, Fla. 8872B, and Fla. 8925. Among these, Fla. 630, Fla. 645, and Fla. 8344 are plum fruit types and all others are large-round fruit types. The phenotype of each line was confirmed before sequencing. Molecular marker-phenotypic trait cosegregation was evaluated among 41 lines/ populations segregating for $j-2$ and among 11 lines that were fixed for the trait. Pedigrees of these materials, including the source of $j-2$ in each, are described in the marker evaluation tables.

Whole-genome shotgun sequencing and SNP detection. We performed whole-genome shotgun sequencing of the 19 lines using Illumina technology. Genomic DNA extraction was performed as described in Li et al. (2018). Genomic DNA was sequenced using the Illumina HiSeq. 2000 at the Cornell 
University Life Sciences Core Laboratories Center. For each line, Bowtie 2 (Langmead and Salzberg, 2012) was used to align the reads to the Heinz 1706 reference sequence. SNPs were predicted from aligned read data using FreeBayes (version 0.9.16-1-gf46d24f; Garrison and Marth, 2012). For marker development, only SNPs that were monomorphic among jointless lines, monomorphic among jointed lines, and polymorphic between these phenotypic classes were considered. SNPs in close proximity to a gene Solyc12g038510 (Soyk et al., 2017) and to BAC clone 121H12 (Yang et al., 2005) were used to develop HRM and dCAPs markers.

Marker development and testing. HRM markers were developed according to the manufacturer's instructions (Roche, Indianapolis, IN). Fluorescence signals were measured using the Roche LightCycler 480 system (Roche) with AccuStart II PCR ToughMix (Quantabio, Beverly, MA) according to the manufacturer's instructions. Amplification of HRM markers used the following temperatures and durations: $95^{\circ} \mathrm{C}$ for $3 \mathrm{~min}$, followed by 42 cycles of $95^{\circ} \mathrm{C}$ for $20 \mathrm{~s} ; 57^{\circ} \mathrm{C}$ for $20 \mathrm{~s}$; $72{ }^{\circ} \mathrm{C}$ for $15 \mathrm{~s}$; and a 10 -min extension at $72{ }^{\circ} \mathrm{C}$. The products from a jointed and a jointless line were sequenced by the Sanger method to validate single-product amplification of the target region.

Two software packages were used for dCAPS primer development: dCAPS Finder 2.0 (Neff et al., 2002; http://helix.wustl.edu/ dcaps/dcaps.html) and Primer-BLAST (Ye et al., 2012; https://www.ncbi.nlm.nih.gov/ tools/primer-blast). The marker was PCR amplified using Phire Hot Start DNA polymerase (TaKaRa, Tokyo, Japan) as per the manufacturer's instructions. Single-product amplification of the target region was validated for a jointed and a jointless line using Sanger sequencing. PCR amplicons were digested using the Dde I restriction enzyme (New England Biolabs, Beverly, MA) according to the manufacturer's instructions, and the digested products were visualized on a $3.0 \%$ agarose gel strained with ethidium bromide $\left(0.05 \mu \mathrm{L} \cdot \mathrm{mL}^{-1}\right)$.

Two HRM markers and one dCAPS marker were used to investigate marker-trait cosegregation among a diverse set of tomato lines fixed or segregating for $j-2$ (Table 1). Leaf discs ( $6 \mathrm{~mm}$ diameter) were individually collected from 3-week-old seedlings grown in a greenhouse. Genomic DNA was extracted using a rapid $\mathrm{NaOH}$-based extraction method as described in Xin et al. (2003), and genotypes were determined as described previously. Plants were grouped according to genotype and then planted in the field and subsequently phenotyped for the jointless trait.

\section{Results}

Whole-genome sequencing was used to discover SNPs between jointless pedicel and jointed pedicel genotypes. Because BAC clone $121 \mathrm{H} 12$ was reported to contain candidate gene(s) for $j$-2 (Yang et al., 2005), nucleotide positions that harbored polymorphic SNPs between two different phenotypic classes and which were near this BAC were selected for molecular marker development (Fig. 1). Two useful SNPs were identified near $54.95 \mathrm{Mbp}$ on chromosome 12, and
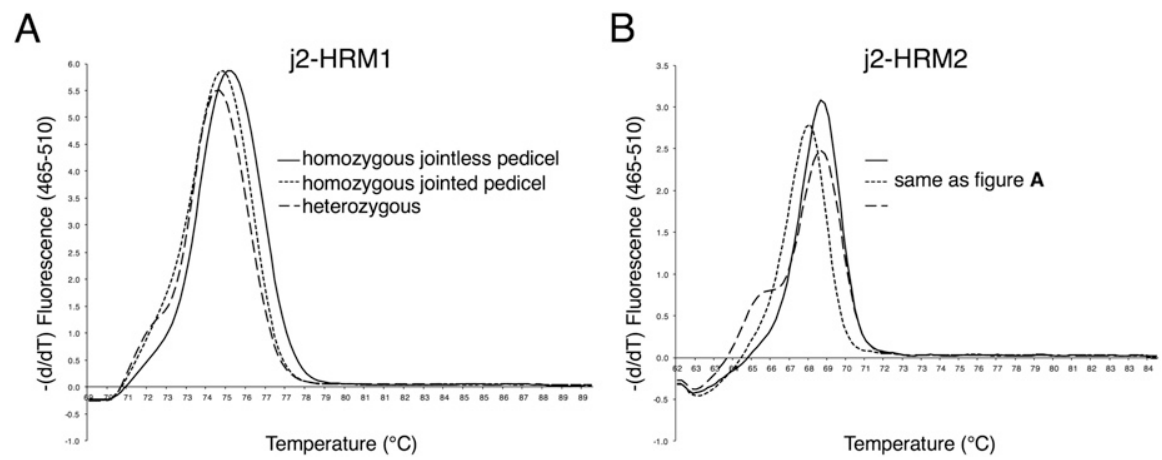

Fig. 3. SNP genotyping of the jointless pedicel trait. For both analyses, a clearly separated curve is observed in the homozygous jointless pedicel genotype, which melted at higher temperatures than the homozygous jointed one. Heterozygous genotype has a different shape than homozygotes in the low melting region. At least three independent experiments per analysis are performed showing similar results. In all three PCR products, data from a single genotype are presented. The LightCycler system was used for melting curve acquisition.

Table 2. Sequence polymorphisms in the 200-kb region across the j2-HRM2 marker.

\begin{tabular}{|c|c|c|c|c|}
\hline \multirow{2}{*}{ Marker } & \multirow{2}{*}{$\begin{array}{l}\text { Position on Chr. } 12 \text { (bp), } \\
\text { SL3.0 assembly }\end{array}$} & \multirow{2}{*}{$\begin{array}{l}\text { Position on Chr. } 12 \text { (bp), } \\
\text { SL2.5 assembly }\end{array}$} & \multicolumn{2}{|c|}{ Genotype $^{z}$} \\
\hline & & & Jointless & Jointed \\
\hline \multirow{40}{*}{ solcap_snp_sl_18995y } & $51,284,392$ & $47,537,462$ & $\mathrm{~T}$ & $\mathrm{C}$ \\
\hline & $51,286,001$ & $47,535,853$ & $\mathrm{~T}$ & $\mathrm{C}$ \\
\hline & $51,287,399$ & $47,534,455$ & A & $\mathrm{C}$ \\
\hline & $51,289,461$ & $47,532,393$ & $\mathrm{C}$ & $\mathrm{T}$ \\
\hline & $51,292,281$ & $47,529,573$ & G & A \\
\hline & $51,295,006$ & $47,526,848$ & $\mathrm{~T}$ & A \\
\hline & $51,309,258$ & $47,512,597$ & A & G \\
\hline & $51,311,102$ & $47,510,753$ & A & $\mathrm{T}$ \\
\hline & $51,328,794$ & $47,493,061$ & $\mathrm{~T}$ & $\mathrm{C}$ \\
\hline & $51,337,139$ & $47,484,717$ & A & $\mathrm{T}$ \\
\hline & $51,344,173$ & $47,477,683$ & A & G \\
\hline & $51,350,358$ & $47,471,498$ & A & $\mathrm{T}$ \\
\hline & $51,356,208$ & $47,465,648$ & A & G \\
\hline & $51,390,786^{x}$ & $47,431,070$ & $\mathbf{T}$ & C \\
\hline & $51,391,262$ & $47,430,594$ & $\mathbf{A}$ & G \\
\hline & $51,393,057$ & $47,428,799$ & C & $\mathbf{A}$ \\
\hline & $51,394,868$ & $47,426,988$ & $\mathbf{T}$ & $\mathrm{C}$ \\
\hline & $51,395,999$ & $47,425,857$ & C & $\mathbf{A}$ \\
\hline & $51,397,210$ & $47,424,646$ & $\mathrm{C}$ & $\mathrm{T}$ \\
\hline & $51,401,085$ & $47,420,770$ & A & $\mathrm{C}$ \\
\hline & $51,411,471$ & $47,410,385$ & $\mathrm{C}$ & $\mathrm{T}$ \\
\hline & $51,417,314$ & $47,404,542$ & A & G \\
\hline & $51,419,916$ & $47,401,940$ & A & $\mathrm{T}$ \\
\hline & $51,427,293$ & $47,394,563$ & $\mathrm{~T}$ & $\mathrm{C}$ \\
\hline & $51,433,514$ & $47,388,342$ & G & A \\
\hline & $51,433,782$ & $47,388,074$ & $\mathrm{~T}$ & $\mathrm{C}$ \\
\hline & $51,438,275$ & $47,383,581$ & A & G \\
\hline & $51,443,687$ & $47,378,169$ & $\mathrm{~T}$ & G \\
\hline & $51,445,435$ & $47,376,420$ & $\mathrm{C}$ & $\mathrm{T}$ \\
\hline & $51,445,851$ & $47,376,005$ & A & G \\
\hline & $51,447,572$ & $47,374,283$ & $\mathrm{C}$ & A \\
\hline & $51,447,602$ & $47,374,254$ & $\mathrm{C}$ & $\mathrm{T}$ \\
\hline & $51,447,843$ & $47,374,013$ & $\mathrm{~T}$ & G \\
\hline & $51,450,639$ & $47,371,217$ & $\mathrm{~T}$ & $\mathrm{C}$ \\
\hline & $51,454,036$ & $47,367,820$ & G & A \\
\hline & $51,457,258$ & $47,364,598$ & $\mathrm{~T}$ & $\mathrm{C}$ \\
\hline & $51,459,743$ & $47,362,113$ & $\mathrm{~T}$ & G \\
\hline & $51,463,629$ & $47,358,227$ & A & G \\
\hline & $51,463,922$ & $47,357,934$ & A & $\mathrm{T}$ \\
\hline & $51,465,764$ & $47,356,092$ & $\mathrm{~T}$ & A \\
\hline
\end{tabular}

${ }^{\mathrm{z}} \mathrm{SNPs}$ that were monomorphic among jointless lines, monomorphic among jointed lines, and polymorphic between these phenotypic classes were considered.

${ }^{\mathrm{y}} \mathrm{A}$ marker identification incorporated in the tomato SolCAP infinium array platform (http://solcap.msu. edu/tomato_genotype_data.shtml).

${ }^{\mathrm{x}} \mathrm{SNPs}$ in the gene Solyc12g038510 were bolded. 


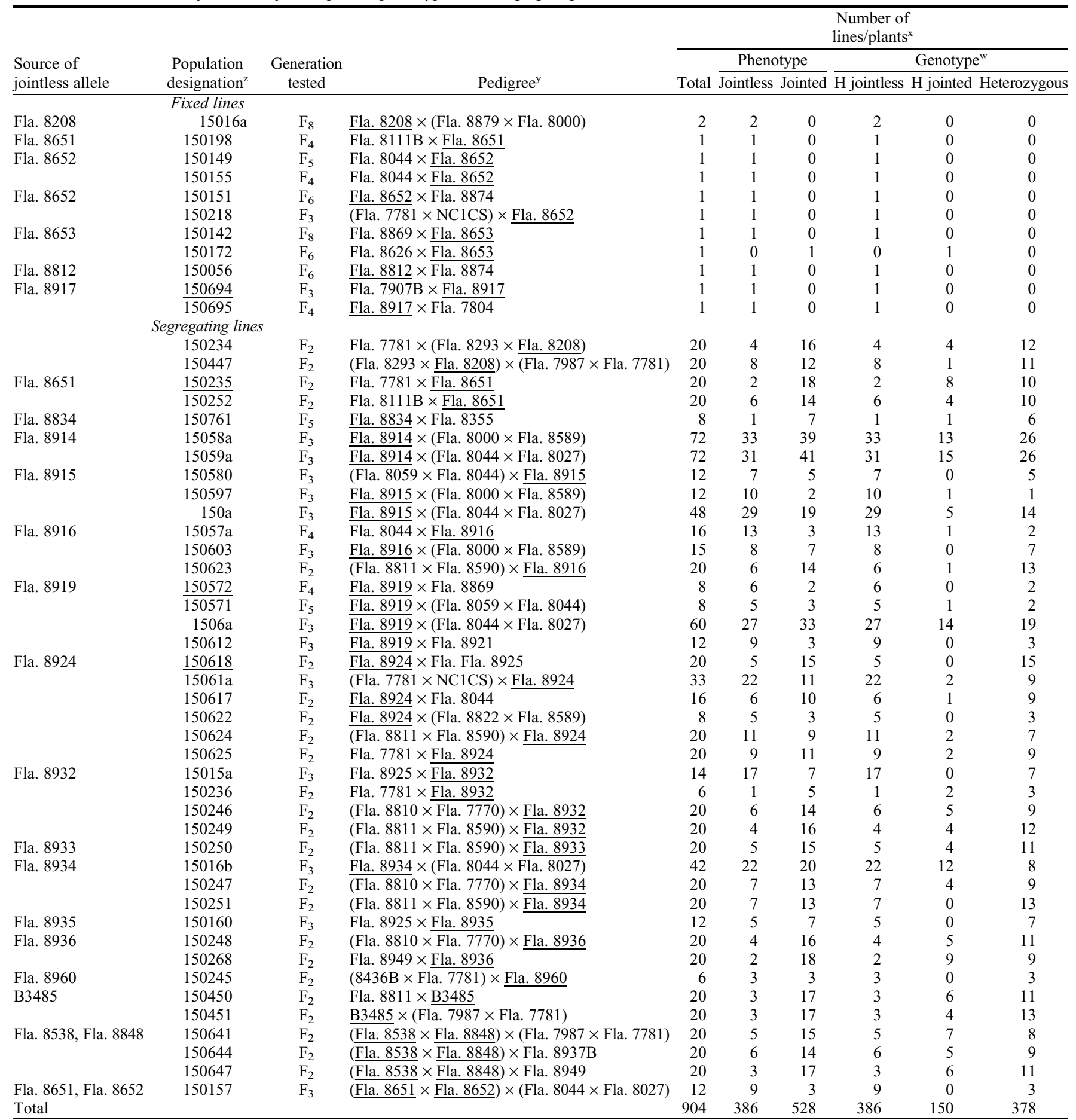

${ }^{2}$ Populations with the same core crossing and same filial generation were grouped together. Populations genotyped by all three markers, j2-dCAPS, j2-HRM1, and j2-HRM2, are underlined.

${ }^{\mathrm{y}}$ Pedigrees indicate the inbred parents used in crosses; where breeding lines were used in crosses, the parents of these are described within parentheses. Jointless parents are underlined.

${ }^{\mathrm{x}}$ Correspond to number of individual lines where genotype/phenotype are fixed and to number of individual plants for segregating lines.

${ }^{\mathrm{w}} \mathrm{H}$ jointless: homozygous jointless pedicel genotype, $\mathrm{H}$ jointed: homozygous jointed.

for genotyping, we tested the association of the marker and the trait in segregating populations of diverse filial generations (Table 3 ). A total of 11 fixed and 41 segregating lines (904 plants) were phenotyped and genotyped in Spring 2015. In all cases, plants with the jointless pedicel phenotype were homozygous for the single larger fragment, and plants with jointed pedicels were either heterozygous or homozygous for the smaller fragment (Fig. 2).

Concurrently, the SNP on which the j2dCAPS marker is based was used for development of a HRM marker (Table 1; Fig. 3A). None of the genotypes with single base $\mathrm{A}$ at $54,951,734$ bp have shown jointless pedicel phenotype (referred to henceforth as j2-HRM1) (Table 4).

We originally initiated the development of a j-2 marker system based on the location of a BAC clone reported by Yang et al. (2005). Recently, however, $j-2$ was attributed to mutations in a gene Solyc12g038510 (Soyk et al., 2017), which is located $\approx 3.5$ 


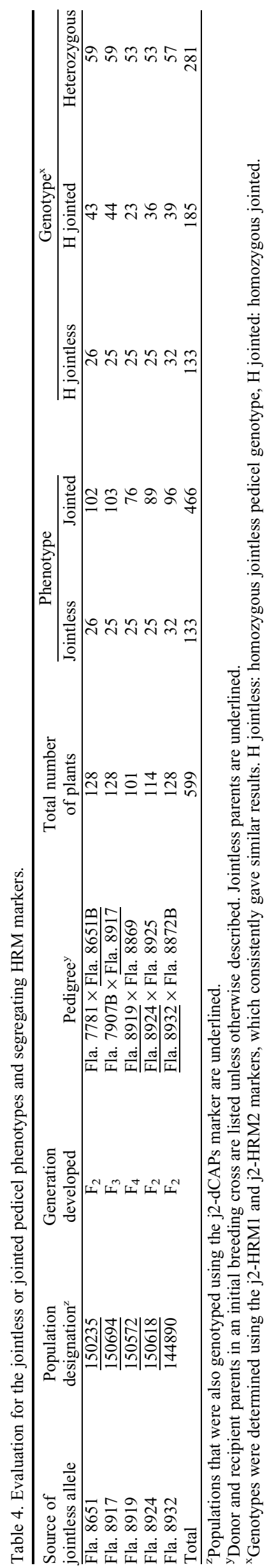

Mbp apart from the BAC. In light of this, we searched for additional polymorphisms near this gene for use in further marker development (Tables 1 and 2; Fig. 1). An [A/C] (adenine to cytosine) SNP located in gene Solyc12g038510 at 51,393,057 bp was successfully converted to a HRM marker and distinguished among jointed and jointless genotypes (Fig. 3B; hereafter, this marker is termed j2-HRM2). Homozygotes had similar shapes in melting curves but their $T_{\mathrm{m}} \mathrm{s}$ differed by up to $1{ }^{\circ} \mathrm{C}$. Heteroduplex products were likewise distinguishable from either homozygote. Both j2-HRM1 (described previously) and j2-HRM2 were used to genotype five segregating populations in Spring 2017 (nearly 600 plants, total) (Table 4). Genotypes for j2-HRM2 showed a perfect link to the jointless pedicel phenotype, and no discordant genotypes between $\mathrm{j} 2$-HRM1 and j2HRM2 were identified.

\section{Discussion}

In this study, molecular markers were developed that can accurately genotype the $j-2$ jointless pedicel locus in tomato. Each of the markers consistently distinguished jointed genotypes from jointless genotypes among the range of breeding materials tested, which represents a large portion of U.S. fresh-market tomato germplasm. The two HRM markers developed in this study are $\approx 3.5 \mathrm{Mbp}$ apart, one marker (j2-HRM2) located at the $j-2$ homolog and the other (j2HRM1) located in the telomere-proximal to that gene. Distinguishable DNA sequence polymorphisms were acquired from wholegenome sequencing data. The sequencing data, which are increasingly available for major crop plants, provided adequate sequence resources to saturate the locus, with the advantage of no ascertainment bias from the analyzed $j-2$ region. The advantages of these markers over presently existing phenotyping efforts are a) genotyping does not require mature (flowering) plants and thus the jointless pedicel phenotype can be screened in seedlings, b) the use of codominant markers will enable more rapid, efficient backcrossing of $j-2$ as opposed to a modified backcrossing approach where selection for the trait is only possible in an $\mathrm{F}_{2}$, and c) the ability to distinguish the heterozygous $J-2 / j-2$ plants from homozygous jointed plants may increase the probability of identifying horticulturally superior plants while ensuring that the jointless trait is maintained, allowing a more judicious allocation of resources for achieving breeding objectives. In addition, the HRM marker system is one that does not rely on variations in the electrophoretic mobility of PCR amplicons for detection of DNA variation, and the SNPs identified in this study can be easily converted to other detection platforms.

Given the high production and labor costs and uncertainties about future availability of labor resources, as well as increasing imports of product from competing markets, the fresh-market tomato industry is under significant pressure to reduce inputs to maintain viability/profitability (McAvoy and OzoresHampton, 2011; Scott et al., 2010; USDA ERS; www.ers.usda.gov/topics/crops/vegetablespulses/trade.aspx). Such circumstances force the industry to seek new production systems to reduce both dependence on farm labor and cost. A transition to mechanical harvest is one potential solution to this challenge, and the availability of improved jointless pedicel cultivars is a necessary component to this solution as stem-free harvest of fruit is essential. Our markers should contribute to increased use of the $j-2$ gene in fresh-market breeding programs, as the locus can now be selected with greater efficiency.

\section{Literature Cited}

Budiman, M.A., S.B. Chang, S. Lee, T.J. Yang, H.B. Zhang, H. de Jong, and R.A. Wing. 2004. Localization of jointless-2 gene in the centromeric region of tomato chromosome 12 based on high resolution genetic and physical mapping. Theor. Appl. Genet. 108:190-196.

Butler, L. 1936. Inherited characters in the tomato. II. Jointless pedicel. J. Hered. 27:25-26.

Davis, J.M. and E.A. Estes. 1993. Spacing and pruning affect growth, yield, and economic returns of staked fresh-market tomatoes. J. Amer. Soc. Hort. Sci. 118:719-725.

Garrison, E. and G. Marth. 2012. Haplotype-based variant detection from short-read sequencing. arXiv preprint arXiv:1207.3907.

Langmead, B. and S. Salzberg. 2012. Fast gappedread alignment with Bowtie 2. Nat. Methods 9:357-359.

Li, J., J. Chitwood, N. Menda, L. Mueller, and S.F. Hutton. 2018. Linkage between the $I-3$ gene for resistance to Fusarium wilt race 3 and increased sensitivity to bacterial spot in tomato. Theor. Appl. Genet. 131:145-155.

Mao, L., D. Begum, H.W. Chuang, M.A. Budiman, E.J. Szymkowiak, E.E. Irish, and R.A. Wing. 2000. JOINTLESS is a MADS-box gene controlling tomato flower abscission zone development. Nature 406:910-913.

McAvoy, E. and M. Ozores-Hampton. 2011. Unique challenges for Florida growers in tomato and pepper Production. Univ. Florida, Inst. Food Agr. Sci., Electronic Data Info. Source, IPM-201. 4 Oct. 2017. <http://edis. ifas.ufl.edu/in $733>$.

Neff, M.M., E. Turk, and M. Kalishman. 2002. Webbased primer design for single nucleotide polymorphism analysis. Trends Genet. 18:613-615.

Pardey, P.G., C. Chan-Kang, S.P. Dehmer, and J.M. Beddow. 2016. Agricultural R\&D is on the move. Nature 537:301-303.

Reynard, G.B. 1961. New source of the $j 2$ gene governing jointless pedicel in tomato. Science 134:2102.

Rick, C.M. 1956. Genetics and systematic studies on accessions of Lycopersicon from the Galapagos Islands. Amer. J. Bot. 43:687-696.

Rick, C.M. 1980. Linkage report: Tomato linkage survey. Rep. Tomato Genet. Coop. 30:2-17.

Scott, J.W., S.F. Hutton, and J. Strobel. 2010. Some highlights from the University of Florida tomato breeding program. Proc. Florida Tomato Inst. 53:9-10.

Scott, J.W., J.R. Myers, P.S. Boches, C.G. Nichols, and F.F. Angell. 2013. Classical genetics and traditional breeding, p. 60-61. In: B.E. Liedl, J.A. Labate, J.R. Stommel, A. Slade, and C. Kole (eds.). Genetics, Genomics, and Breeding of Tomato. CRC Press, NW. 
Soyk, S., Z.H. Lemmon, M. Oved, J. Fisher, K.L. Liberatore, S.J. Park, A. Goren, K. Jiang, A. Ramos, E. van der Knaap, J. Van Eck, D. Zamir, Y. Eshed, and Z.B. Lippman. 2017. Bypassing negative epistasis on yield in tomato imposed by a domestication gene. Cell 169: 1142-1155.e12.

Wing, R.A., H.B. Zhang, and S.D. Tanksley. 1994. Map-based cloning in crop plants. Tomato as a model system: I. Genetic and physical mapping of jointless. Mol. Gen. Genet. 242:681688.

Xin, Z., J.P. Velten, M.J. Oliver, and J.J. Burke. 2003. High-throughput DNA extraction method suitable for PCR. Biotechniques 34:820 824.

Yang, T.J., S. Lee, S.B. Chang, Y. Yu, H. de Jong, and R.A. Wing. 2005. In-depth sequence analysis of the tomato chromosome 12 centromeric region: Identification of a large CAA block and characterization of pericentromere retrotranposons. Chromosoma 114:103-117.

Ye, J., G. Coulouris, I. Zaretskaya, I. Cutcutache, S. Rozen, and T.L. Madden. 2012. PrimerBLAST: A tool to design target-specific primers for polymerase chain reaction. BMC Bioinformatics 13:134.

Zahara, M.B. and S.S. Johnson. 1981. Cost comparison of hand harvest and mechanical harvest of mature green tomatoes. Univ. California, Veg. Res. and Info. Ctr. 4 Oct. 2017. <https:// ucanr.edu/repositoryfiles/ca3507p7-61772.pdf> .

Zahara, M.B. and R.W. Scheuerman. 1988. Handharvesting jointless vs. jointed-stem tomatoes: Jointless-stem fresh-market varieties take much less time to pick than jointed types. Univ. California, Veg. Res. and Info. Ctr. 4 Oct. 2017. $<$ http://ucce.ucdavis.edu/files/repositoryfiles/ ca4203p14-68779.pdf>

Zhang, H.B., M.A. Budiman, and R.A. Wing. 2000 Genetic mapping of jointless-2 to tomato chromosome 12 using RFLP and RAPD markers. Theor. Appl. Genet. 100:1183-1189. 